\title{
Harm A. Weber academic center, post-occupancy building performance and comfort perceptions
}

\author{
Keelan P. Kaiser ${ }^{1}$, David M. Ogoli, $\mathrm{PhD}^{2}$, and Malcolm Cook, $\mathrm{PhD}^{3}$ \\ ${ }^{1}$ The School of the Art Institute of Chicago, Chicago, Illinois \\ 2Judson University, Elgin, Illinois \\ ${ }^{3}$ Loughborough University, Leicestershire, United Kingdom
}

\begin{abstract}
The Weber Center at Judson University, a mixed mode, naturally ventilated building in a continental climate, has been in operation for just over a year, with initial occupancy in August 2007. This paper compares the design objectives and building performance expectations against the first year of actual energy consumption in a first of a series of post-occupancy evaluations. The paper contrasts the building performance with general user satisfaction and perceptions of comfort through a postoccupancy evaluation of user surveys and interviews. The innovations involved in this building, particularly mechanical strategies atypical in contemporary practice within this climate and region, have introduced some interesting problems that have been documented in the post-occupancy evaluation process, while confirming many of the original intentions of the design.
\end{abstract}

Conference theme: Building performance studies, zero energy, and carbon-neutral buildings

Keywords: post-occupancy evaluation, building performance, comfort, natural ventilation, daylighting

\section{INTRODUCTION}

The Weber Center, designed by Short and Associates (design architect) and Burnidge Cassell and Associates (record architect), is a first of its kind in the continental climate region of Chicago, IL. The result of a winning entry in a 2001 invited design competition for a new School of Art, Design and Architecture combined with a Central Library, the four story building occupies approximately 88,000 gross square feet on the Judson University campus along the Fox River in Elgin, IL. Construction commenced in 2005 and concluded in July 2007, with final commissioning and occupancy in August 2007.

The facility employs a hybrid natural ventilation strategy that reduces heating and cooling loads during swing months of the spring and fall; and uses night flushing accompanying a high thermal mass of precast concrete. Other passive strategies, including modest passive solar and shading, in conjunction with significant daylighting reduces loads on heating, cooling and lighting (Fig. 1). An extensive landscape architecture complements the new facility with on-site storm water management and native prairie and habitat restoration.

$50 \%$ of the carbon emissions generated by electricity usage of the building is offset through a local renewable energy certificate agreement.

Pre-construction modeling was conducted early in the design stages, and included computational fluid dynamics modeling (De Montfort University Institute of Energy and Sustainable Development), as well as

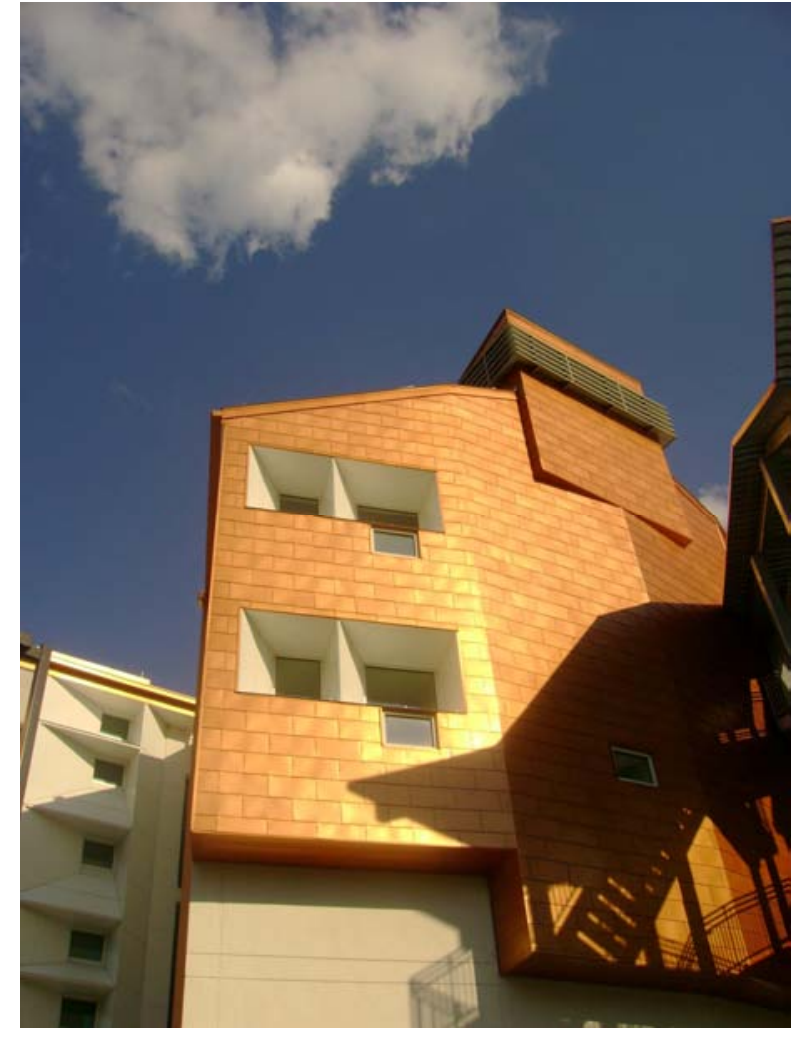

Figure 1: Exterior southwest view. Source: (Author 2007) 
experimental and theoretical modeling of key aspects of the building integrated photovoltaics and natural ventilation in the south facade (University of Cambridge BP Institute for Multiphase Flow). The preliminary modeling provided the basis for design decision-making by the record architects and particularly their consulting mechanical engineers KJWW.

The facility houses a professional architecture school and a central library making it a remarkable learning context that positions sustainable building as a core architectural education priority (Fig.2).

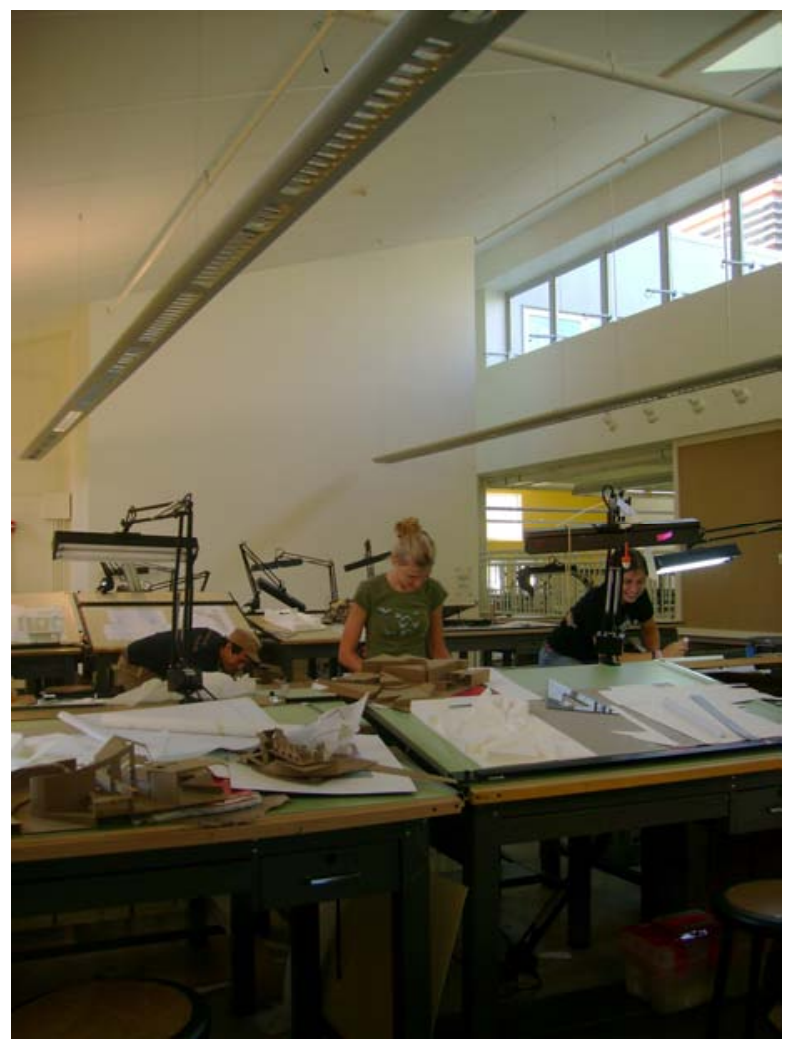

Figure 2: Architecture studios. Source: (Author 2007)

One of the promising values to the institution during the competition selection process in 2001 was a proposed energy savings of $42-47 \%$ over a conventional academic building proposed by the Short scheme. The competition jury, composed of a cross section of users, administrators and trustees of the University, perceived that these savings were valuable not only economically, but also philosophically as an institution. Ultimately, the prospect of the institution building an architecture school that would be "one of a kind" because of its environmental approach according to jury moderator Carol Ross Barney, FAIA, was the kind of distinction the jury responded to, and the Short scheme was selected.

The process of design and construction was not without its challenges. Neither the record architect nor the construction manager/general contracting firm had built a high performance building to date, and neither had any experience whatsoever with such an unusual natural ventilation approach. The mechanical engineers had some experience with ventilation strategies but certainly not at the scale pursued in the Short scheme. The entire design team, and it was a collaborative process by necessity if not design, entered into a steep learning curve. While the process remained in a fundraising stage between 2001 and 2003, the design team, pursued many iterations wedding the specific programmatic needs with the energy scheming, some of which were at odds (e.g. library uses and humidity occurring in naturally ventilated air).

Ultimately a pre-cast concrete structure that was exposed to the interior and insulated and sealed on the exterior was developed (Fig. 3, 4).

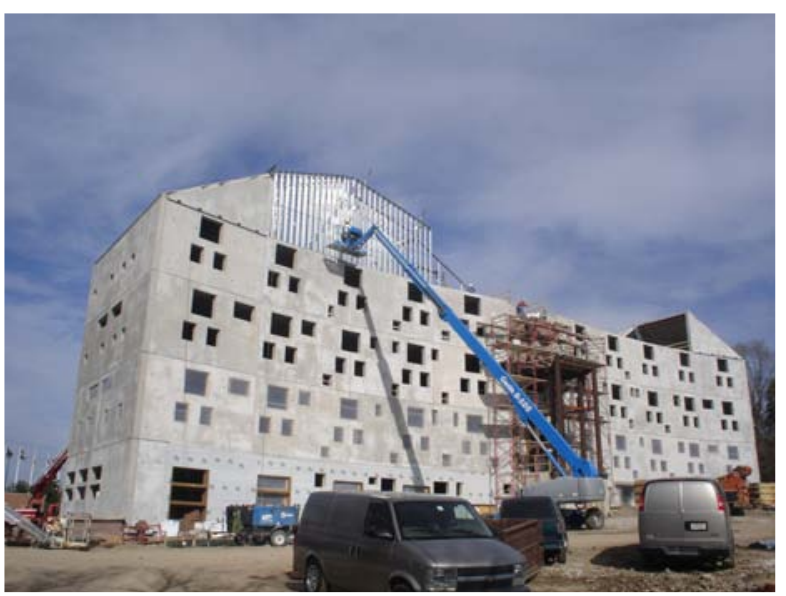

Figure 3: Pre-cast concrete structure. Source: (Author 2006)

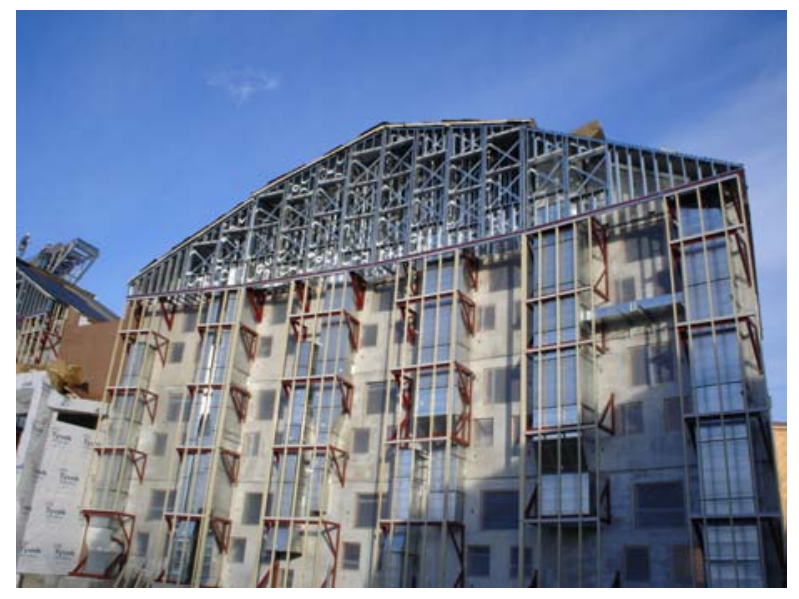

Figure 4: Pre-cast concrete structure with return air stacks during rough framing. Source: (Author 2006)

The building employs two primary types of natural ventilation circuits. The central library/architecture studio block employs an edge in/center out type. The academic wing employs an edge in/edge out type (Lomas, 2007). The two types function independently of one another in the complicated mixed program of open library and cellular academic functions (Fig. 5). 


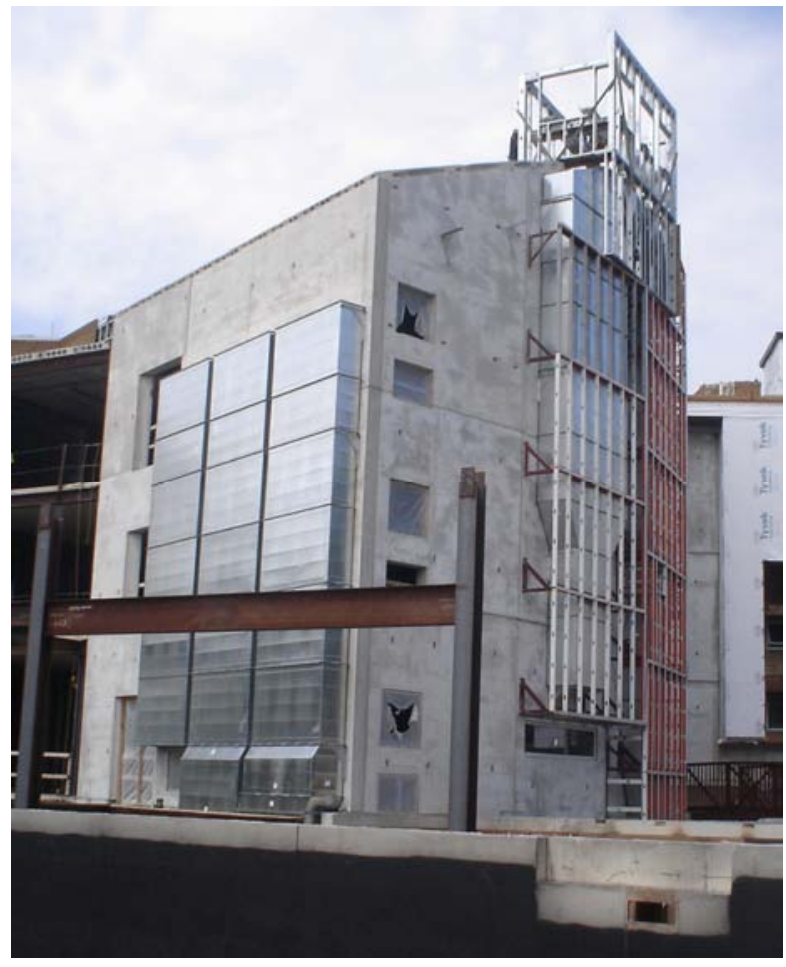

Figure 5: Pre-cast concrete structure with supply air ducts (left) and return air duct/stack (right), during rough framing. Source: (Author 2006)

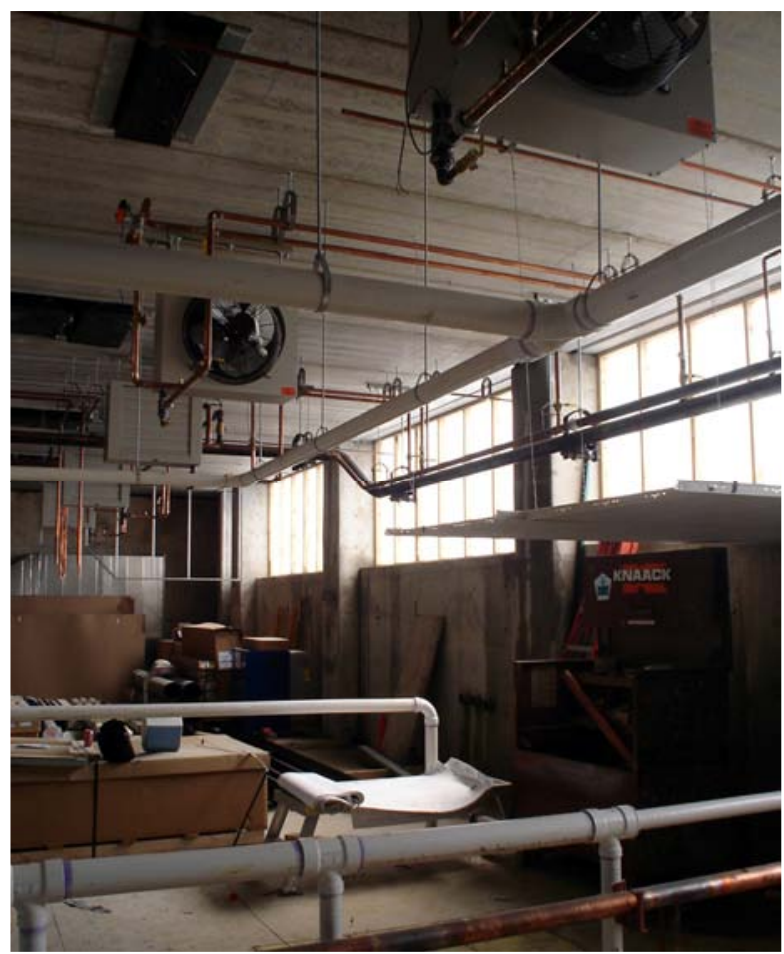

Figure 6: External fresh air intake supplies the lower level insulated ceiling plenum (air travels from right to left in this construction photo). Source: (Author 2006)
Fresh air is drawn into the building through the ceiling plenum at the ground level. Intake filters, screens and automated dampers control the intake air at this area of the building envelope. Hot water unit heaters occupy the ground level plenum space for tempering of air during the swing seasons when outdoor temperatures are between 42-60 degrees Fahrenheit. Air is then supplied through the four-story structure through a glazed central atrium (Fig. 6, 7).

The stack elements that pull the ventilation throughout the building are applied to the exterior of the pre-cast structure in most situations, and exhaust air above the roof in three multidirectional termini types (Fig. 8).

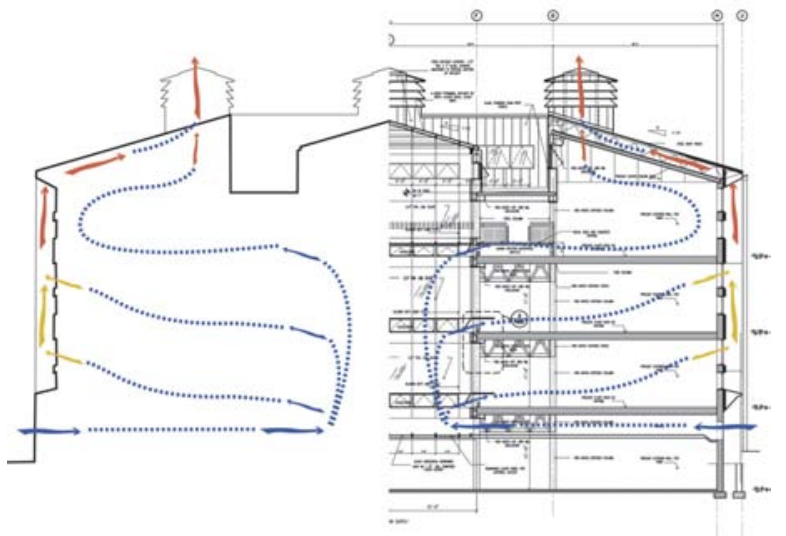

Figure 7: Airflow diagram through intake supply, central atrium, individual floor plates, and roof exhaust at library/architecture studios. Source: (Author 2006)

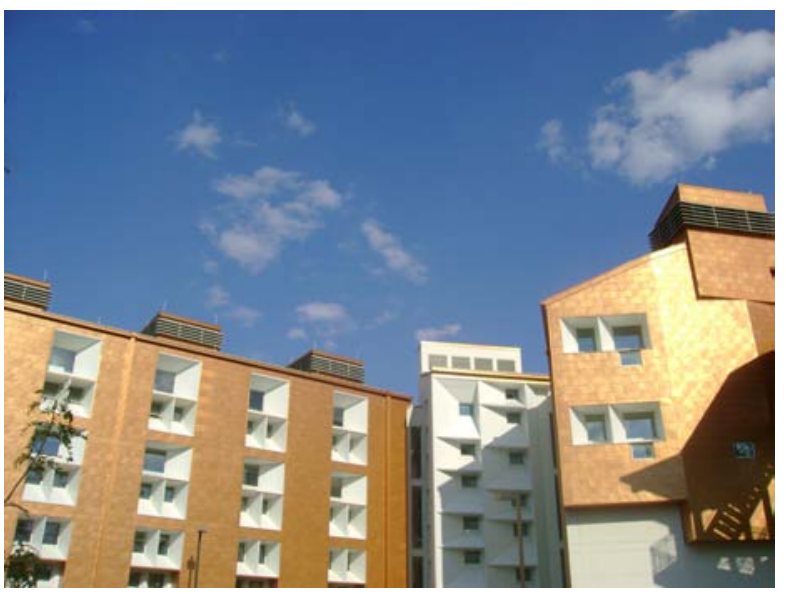

Figure 8: Stack exhaust termini types. Source: (Author 2007)

\section{ENERGY PERFORMANCE - YEAR ONE}

One component of this paper is the evaluation of the overall energy performance over a twelve-month period between $2 / 08$ and $1 / 09$. This date range provides the most accurate and complete twelve- month data set available during the first 18 months of operation. The data was drawn from the building management system and compared against utility bills for accuracy. 


\subsection{Energy cost budget - predictions}

The mechanical engineers prepared energy cost budgets for the building comparing a base case against the design case. The software used to calculate the energy cost budget was TRACE 700 v6.1.1. These budgets estimated a conventional ASHRAE 90.1 total annual base case energy consumption of $7423.3 \mathrm{MBtu}$, including 5621.0 MBtu in electricity and 1802.3 MBtu in gas. The design case energy consumption total was estimated at 6061.7 MBtu, with 5026.4 MBtu in electricity and 1035.3 MBtu in gas. The anticipated electricity savings were modeled at $10.6 \%$, while gas savings were modeled at $42.6 \%$, for a total predicted energy savings of $18.3 \%$ over the base code (Table 1 ).

Table 1: Annual energy use budget: base case vs. design case, \% difference

\begin{tabular}{cccc}
\hline & $\begin{array}{c}\text { ASHRAE } \\
\text { Base } \\
\text { Case } \\
\text { Energy } \\
(\mathrm{MMBtu})\end{array}$ & $\begin{array}{c}\text { HWAC } \\
\text { Design } \\
\text { Case } \\
\text { Energy } \\
(\mathrm{MMBtu})\end{array}$ & $\begin{array}{c}\text { \% Difference } \\
\text { from Base } \\
\text { Case }\end{array}$ \\
\hline $\begin{array}{c}\text { Electricity } \\
\text { Gas }\end{array}$ & 5621.0 & 5026.4 & $10.6 \%$ \\
Total & 1802.3 & 1035.3 & $42.6 \%$ \\
& 7423.3 & 6061.7 & $18.3 \%$ \\
\hline
\end{tabular}

The predicted gas savings were comparable to the original design goals of the Short scheme (42-47\% savings in the earliest design modeling in 2001). The electricity savings were not as easy to achieve in the design case model. Some of the barriers, according to the mechanical engineers, included: 1) programmatic flexibility in the spaces required increased density of plugs and fixtures, 2) most of the automatic lighting was value engineered out of the project due to budget constraints and predictions that manually operated fixtures by aware users might yield better performance, and 3 ) some of the savings originally anticipated by reduced fan use were not able to be realized. As a result, the design case anticipated a modest $18.3 \%$ savings.

\subsection{HWAC actual energy use}

Collecting data from the building management system during the months of $12 / 08-12 / 09$, an estimated total energy consumption of 6203.7 MBtu was tracked during the twelve-month period between 2/08 - 1/09 indicating a reasonably accurate energy use prediction during the first year. The actual usage differs from the predicted usage by approximately $2.3 \%$. Compared to the base case energy model, HWAC operated with a $16.4 \%$ energy reduction (Table 2 ).

The building performance in electricity is quite good, while there appear to be chronic issues in gas consumption.

Comparing the actual energy use with the design case shows an understandably narrower margin of energy reduction in electricity use, and further spike in gas use. This resulted in a $2.3 \%$ increase in overall energy use (Table 3).
Table 2: Annual Energy Use Comparison: Base Case vs. Actual Use, \% Actual Energy Difference

\begin{tabular}{cccc}
\hline & $\begin{array}{c}\text { ASHRAE } \\
\text { Base } \\
\text { Case } \\
\text { Energy } \\
\text { (MMBtu) }\end{array}$ & $\begin{array}{c}\text { HWAC } \\
\text { Actual } \\
\text { Energy } \\
\text { Use } \\
\text { (MMBtu) }\end{array}$ & $\begin{array}{c}\% \\
\text { Difference } \\
\text { from Base } \\
\text { Case }\end{array}$ \\
\hline Electricity & 5621.0 & 3324.7 & $40.9 \%$ \\
Gas & 1802.3 & 2879.1 & $159.7 \%$ \\
Total & 7423.3 & 6203.7 & $16.4 \%$ \\
\hline
\end{tabular}

Table 3: Annual energy use comparison: design case vs. actual use, $\%$ actual energy difference

\begin{tabular}{cccc}
\hline & $\begin{array}{c}\text { HWAC } \\
\text { Design } \\
\text { Case } \\
\text { Energy } \\
\text { (MMBtu) }\end{array}$ & $\begin{array}{c}\text { HWAC } \\
\text { Actual } \\
\text { Energy } \\
\text { Use } \\
\text { (MMBtu) }\end{array}$ & $\begin{array}{c}\% \\
\text { Difference } \\
\text { from Design } \\
\text { Case }\end{array}$ \\
\hline Electricity & 5026.4 & 3324.7 & $33.9 \%$ \\
Gas & 1035.3 & 2879.1 & $278.1 \%$ \\
Total & 6061.7 & 6203.7 & $102.3 \%$ \\
\hline
\end{tabular}

While the total energy use amount seems good at first glance, it should be noted that the design case energy predictions were far below the 2001 estimates of 42$47 \%$ overall energy savings. The revelation of actual gas use against the modeled predictions has prompted diagnosis of the problem by the mechanical and commissioning engineers. Some preliminary considerations include leaky dampers or building envelope, damper operating errors, boilers not running as efficiently as designed, the system waiting too long to switch from natural to mechanical mode, and the possibility of poor energy modeling due to the uniqueness of the building. More work fine-tuning the system is underway as a result of this paper.

\subsection{The important role of thermal mass}

One performance factor central to the operation of this facility is the presence of a significant amount of internally exposed pre-cast concrete for use as thermal mass. In a mixed-mode building of this kind, this is an important mechanism for maximizing the period of natural ventilation to reduce the cooling load. This is accomplished by a combination of exposed thermal mass, night flushing, and mechanized supply and exhaust damper. While it remains unclear the degree of energy saving due to night flushing for passive tempering of supply air, it is clear that the system is moving air through the building as intended.

The following overviews of temperature measurements and comparisons over three typical seasons and periods of time demonstrates the stabilizing power of thermal mass in passively affecting the heating and cooling loads of the HWAC.

During summer months, the continental climatic conditions require air conditioning to control the temperature and moisture of the incoming air. During 
these periods the air temperature inside the HWAC is controlled to within the range of approximately $72-76^{\circ} \mathrm{F}$ (Figure 9).

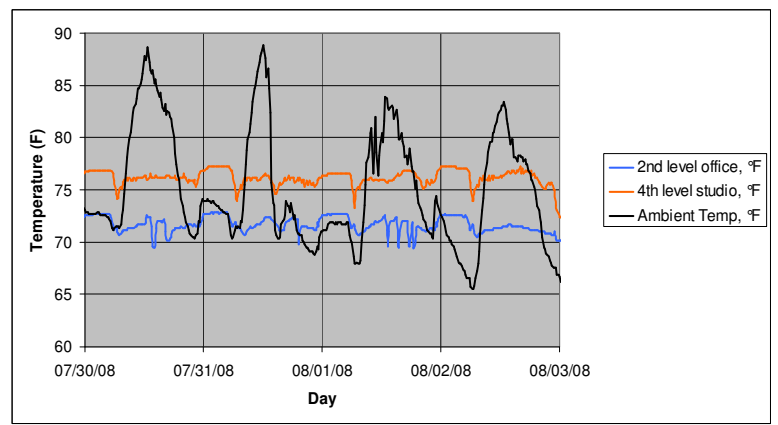

Figure 9: Temperature measurements during a 4-day summer period

During the swing months of spring and fall, where little or no air conditioning is used for the majority of operating hours, the temperature inside the building is determined by the combined temperature of the air entering the space as well as the temperature of the surrounding thermal mass (Figure 10).

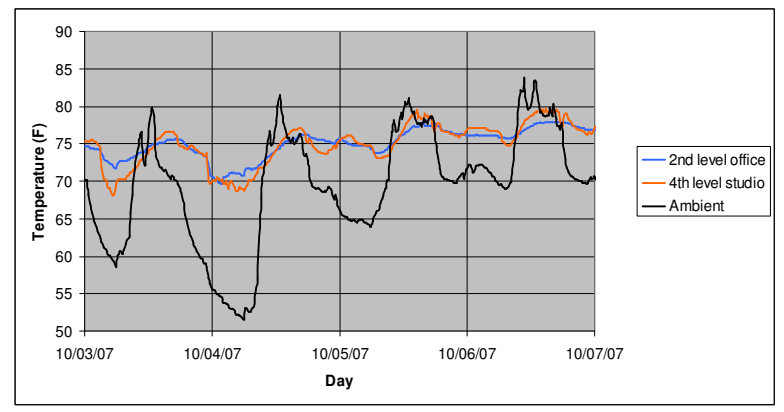

Figure 10: Temperature measurements during a 4-day fall (swing) period

The winter months engage the mechanical system more fully, representing a more conventional comparison of internal and external temperatures. The role of the thermal mass is neutralized as air temperatures are stabilized due to constant mechanical treatment of air (Figure 11).

The figures show how internal air temperature 'lags' behind the ambient temperature due to the thermal mass of the building, thus providing passive cooling during the early hours of the following day and reducing the need for air conditioning. Note that the temperature perceived by the occupants (the operative temperature) could be lower than the (air) temperatures shown if the surrounding surfaces are cooler than the incoming air temperature. This is likely to be the case following successful night ventilation.

Substantial work remains to efficiently manage the building systems to realize both energy savings and ensure adequate user comfort. The original design set points of 70-77 degrees Fahrenheit were reduced and narrowed to 69-74 degrees Fahrenheit due to user comfort concerns. Periodic user complaints about warmth, humidity, and/or airflow rates during the summer illuminate the need for further refinements in operations.

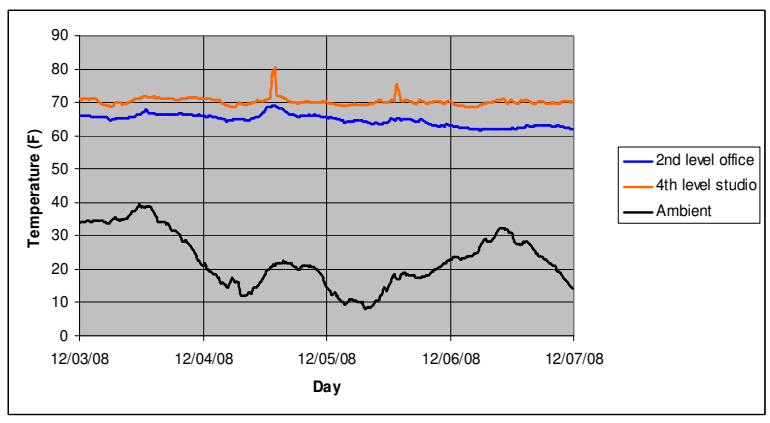

Figure 11: Temperature measurements during a 4-day fall period

\subsection{Energy use conclusions}

The energy use by the HWAC facility during the first year of operation was approximately $70.5 \mathrm{KBtu}$ per gross square feet per year and approximately 17.7 MBtu per person per year based on an average occupancy of 350 users. While both of these estimates are of limited value because of the complexity of the programmatic uses and hours of operation, they do provide initial benchmarks for usage rates for future comparisons.

Future energy use calculations will focus on comparative studies of similar building type and scope (e.g. De Montfort University Queens building, et al) as well as finer grain studies of building performance, particularly in the swing months where the HWAC is expected to deliver its most notable performance of minimizing mechanical cooling needs and the summer where night flushing promises some performance benefit.

\section{USER PERCEPTIONS}

The second component of our study draws from user awareness of energy conservation measures in the HWAC and user perceptions of comfort. Questions related to comfort were administered through a survey. The survey was collaboratively generated with a colleague in Social Sciences, and sought to capture base perceptions broadly defined as awareness, comfort, behavior and assessment. Each question used a differential scale ranging from 3 to 5 points, distributed via email through an interactive digital form. The completed surveys were emailed to the authors for tabulation (Table 4).

\subsection{User awareness}

To establish an understanding of the degree to which building users are aware of their environment, we shaped questions that measure awareness of energy conservation concepts as they relate to the built 
Table 4: Sample voting graphic, 5-point scale

\begin{tabular}{ccc}
\hline SCALE & COMORT & VOTE \\
\hline+2 & Very Satisfied & \\
+1 & Satisfied & \\
0 & Neutral & \\
-1 & Slightly & \\
-2 & Uncomfortable & \\
\hline
\end{tabular}

environment. We assumed that a range of awareness would result based upon the user knowledge, level of education, or staff role. Questions probed knowledge of energy consumption in buildings and carbon emissions, conservation goals of the building, technologies employed within the building, actual energy savings, and their own behavior. From these responses, we expected to gain a better understanding of the building user, their awareness of energy conservation as a broad subject, and their specific concern for this particular building performing well.

These questions were followed by inquiries regarding building systems awareness. They included inquiries regarding knowledge of the unique mechanical system at work in the building, whether or not they were aware of the building making automatic adjustments (e.g. audibly noticing dampers opening and closing), and a perception whether the system was operating properly in their area of survey (Table 5).

Table 5: Overall awareness of energy measures in HWAC

\begin{tabular}{ccc}
\hline Very Aware & Aware & Unaware \\
\hline $42.4 \%$ & $35.3 \%$ & $22.3 \%$ \\
\hline
\end{tabular}

One area of intense user awareness is that the building is changing throughout the day. Actuators open and close dampers, airflow rates change periodically, and lights turn on when entering offices. $65.2 \%$ of respondents reported being "very aware" of mechanical systems changes throughout the day. Conversely, the same amount of respondents was unaware of actual energy savings for HWAC to date; a nod to the need for more attention to informing users of building performance.

\subsection{User comfort}

User comfort is more ambiguous and requires further investigation. Anecdotal information suggests general satisfaction with the building thus far in its operation with some notable exceptions. Temperature regulation seems difficult in many spaces, set points are spread wide resulting in spaces not maintaining steady temperatures from day to day. Airflow regulation in specific areas, like the main classrooms, is disruptive at times due to changes in airflow or slight howling in the ducts as air moves through them. The most vexing problem to date however is the acoustic issues that plague the new building. The exposed pre-cast concrete thermal mass has its consequences: a very acoustically live building.

However, building users are very satisfied with perceptions of comfort, health and wellness related to daylighting. $56.5 \%$ of respondents noted that they were either satisfied or very satisfied with daylighting in their spaces.

While many of the noted items can be adjusted, some may require significant adaptations. Still, for this initial survey at least, user comfort as a whole seems moderately good (Table 6).

Table 6: Overall comfort using HWAC

\begin{tabular}{ccccc}
\hline $\begin{array}{c}\text { Very } \\
\text { Sat. }\end{array}$ & Sat. & Neutral & $\begin{array}{c}\text { Slightly } \\
\text { Uncomf. }\end{array}$ & Uncomf. \\
\hline $19.9 \%$ & $34.8 \%$ & $16.1 \%$ & $21.1 \%$ & $8.1 \%$ \\
\hline
\end{tabular}

\subsection{User behavior}

The survey also attempted to measure the degree to which building users changed their behavior as a result of working within the HWAC. Early in the design of the facility numerous conversations with the designers touched on user comfort and user ranges of comfort. Because of the nature of uses involved in the building, a library and academic classrooms, studios and office, a calculated risk was taken to begin operations with a wide range of set points, beyond the conventional ASHRAE requirements. Unfortunately, the outdoor temperature and humidity levels in August 2007 at initial occupancy were brutal, users were not comfortable, and set points were tightened as noted above. As the building has continued in operation from those early adjustments, we wanted to try to measure user adaptation to the unique demands of the building. Were users layering clothing more than previously to modulate their own comfort? Were users more tolerant of the wider temperature set points because of their awareness of the potential energy saving benefits? We found that the building has changed the general behavior of 1:2 users (Table 7).

Table 7: Changed behaviors as a result of HWAC

\begin{tabular}{ccc}
\hline Yes & No & N/A \\
\hline $47.8 \%$ & $42.4 \%$ & $9.8 \%$ \\
\hline
\end{tabular}

More investigation into this area will be pursued in the future, especially given that the users who report uncomfortable conditions are sometimes modulating their spaces with small space heaters in the winter and desktop fans in the summer. These are, of course, barriers to energy performance and would not be necessary if discrete cellular spaces were both performing optimally and comfortable to work in.

\subsection{Assessment and values}

The final question set in the survey addressed the degree to which users appreciated a connection between their health and wellness and the built environment of the HWAC. Questions probed user 
perceptions of relationships between health and wellness with: fresh air, daylighting, energy efficiency, and knowledge of the technologies deployed. We found that survey respondents did make a soft connection between their own perceptions of health and wellness, and the features of the HWAC (Table 8).

Table 8: Value health and welfare aspects of HWAC

\begin{tabular}{ccccc}
\hline $\begin{array}{c}\text { Very } \\
\text { High }\end{array}$ & High & Neutral & Low & Very Low \\
\hline $7.8 \%$ & $32.2 \%$ & $35.7 \%$ & $11.3 \%$ & $13.0 \%$ \\
\hline
\end{tabular}

From a perspective of tracking values of users, one can see that though increased air changes and daylighting both increase health and wellness as a general principle, the respondents were soft in linking them together in this case. For example, only $34.8 \%$ of the users perceived that their health and wellness was highly improved because of the natural ventilation and $39.1 \%$ of the users perceived that their health and wellness was highly improved because of daylighting in the building. The mean scores are just slightly above neutral. It remains unclear whether these rankings reflect a lack of education on health and wellness issues, or the building is not explicit in its value-added role.

\section{CONCLUSIONS}

It is clear that the first eighteen months of operation of the HWAC facility have yielded mixed results. One immediate value of this study was the identification of poor performance in the category of gas consumption. The subsequent troubleshooting of the deviations between the energy model and actual performance are of immediate value to the owner. This is a testimony to the value of the measurement and verification exercise taking place post-commissioning when the performance of a building can be studied over time. Without this study, the excessive gas consumption of the building may have continued for some time without notice.

It is also clear that the daylighting strategies for this building have yielded success in terms of energy consumption (apparently), even though some automated controls were sacrificed during value engineering. A valuable follow up to this study is the monitoring of the lighting loads for the building isolated from the rest of the electric loads to evaluate how the design case modeling of $1.75 \mathrm{~kW} / \mathrm{s}$.f. compares to actual usage.

Another follow up study should be engaged that tracks the first 1-3 years of natural ventilation mode operation. This study would yield valuable information regarding the cost benefit of including the hybrid natural ventilation system. It remains unclear whether this system is competitive with conventional geothermal, for instance. It could very well be that since the two are more or less mutually exclusive (in that they both benefit from energy savings in swing months), that geothermal may be a more successful design strategy in the continental climate. More study into the subtleties of the strengths and weaknesses of these and other renewable energy strategies seems warranted before the hybrid natural ventilation model can be called a legitimate approach in this climate.

Also, it remains clear that building user education was underestimated at initial occupancy of the HWAC, and more concentrated work remains to be conducted in this area. While it is encouraging to observe that building users in general do feel moderately comfortable and have adapted, or not, to the unique nature of this building, energy usage may drop further and user perceptions of comfort may increase with a more robust user education/information program.

\section{ACKNOWLEDGMENT}

The authors would like to thank KJWW engineer Wade Ross for his assistance in evaluating some of the data contained in this paper and Dr. Marsha Vaughn, Judson University Department of Social Sciences, for assistance in editing the environmental comfort survey. Finally, the authors commend the work of Judson University graduate students Matt Ackerman and Ken Nadolski in assisting with the preparation of data for this paper.

\section{REFERENCES}

Lomas, K. 2007. Architectural design of an advanced naturally ventilated building form. Publisher: Energy and Buildings.

Lomas, K., Cook, M., Fiala, D., 2007. Low energy architecture for a severe US climate: Design and evaluation of a hybrid ventilation strategy. Publisher: Energy and Buildings.

Short, C.A., Lomas, K. 2007. Exploiting a hybrid environmental design strategy in a US continental climate. Publisher: Building Research \& Information. 